\title{
Eficácia de Herbicidas no Controle de Plantas daninhas e Seletividade Em Leguminosas de Cobertura e Cupuaçuzeiro ${ }^{1}$
}

\author{
Efficacy of Herbicides in Weed Control and Selectivity in Cover Leguminous and Cupuassu
}

\author{
SILVA, J.F. ${ }^{2}$, BUENO, C.R. ${ }^{3}$ e SOUZA, A.G.C. ${ }^{4}$
}

\begin{abstract}
RESUMO - O cupuaçuzeiro Theobroma grandiflorum é uma fruteira típica da Amazônia. O seu fruto, o cupuaçu, é um dos mais populares da região e apresenta crescente aumento de demanda devido às suas características organolépticas e diversidade de uso na agroindústria. O seu cultivo, no entanto, ainda é rústico e a produção é muito afetada pela interferência das plantas daninhas. O objetivo deste trabalho foi avaliar a eficácia dos herbicidas alachlor e haloxyfop no controle das plantas daninhas e a seletividade para as leguminosas Mucuna cochinchinensis e Pueraria phaseoloides e para plantas jovens de cupuaçu. O experimento foi instalado no campo, para avaliar o efeito dos herbicidas sobre a produção de matéria seca da parte aérea e o índice de área foliar (IAF) das plantas daninhas e das leguminosas e a toxicidade às plantas de cupuaçu. $\mathrm{O}$ alachlor, na dose de $4,0 \mathrm{~kg} \mathrm{ha}^{1}$, reduziu $75,60 \%$ da produção de matéria seca e $64,02 \%$ do IAF das plantas daninhas, enquanto o haloxyfop, na dose de $0,24 \mathrm{~kg} \mathrm{ha}^{1}$, inibiu $62,51 \%$ do acúmulo de matéria seca e $64,23 \%$ do IAF. As leguminosas $M$. cochinchinensis e $P$. phaseoloides foram tolerantes aos herbicidas. O haloxyfop, na dose de $0,12 \mathrm{~kg} \mathrm{ha}^{-1}$, estimulou a produção de matéria seca da parte aérea e o IAF em $180,15 \%$ e $146,68 \%$, respectivamente. Os herbicidas não causaram injúrias às plantas de cupuaçu e às leguminosas e apresentaram controle das plantas daninhas acima de $60 \%$.
\end{abstract}

Palavras-chave: invasoras, fruteira nativa, Theobroma grandiflorum, Amazônia.

ABSTRACT - The Cupuassu tree Theobroma grandflorum is a typical Amazonian plant. Its fruit, the cupuassu, is one of the most popular fruits in the region with an increasing demand due to its organoleptic characteristics and multi use by the agro industry. Its cultivation, however, is still very rudimentar and its production is highly affected by weeds. The objective of this study is to evaluate the effects of the herbicides alachlor and haloxyfop on weed control and selectivity for the leguminous plants Mucuna cochinchinensis and Pueraria phaseoloides and young cupuassu trees. This experiment was conducted under field conditions to evaluate the effect of herbicides on shoot dry matter production and leaf area index (LAI) of the weeds and leguminous plants and their phytotoxicity to cupuassu trees. Regarding the weeds, alachlor applied at $4.00 \mathrm{~kg} \mathrm{ha}{ }^{1}$ reduced dry matter production by $75.60 \%$ and LAI by $64.02 \%$, whereas haloxyfop inhibited $62.51 \%$ of the dry matter accumulation and $64.23 \%$ of LAI. The herbicides were selective to the leguminous plants and haloxyfop at $0.12 \mathrm{~kg} \mathrm{ha}^{1}$ stimulated dry matter production of the aerial part in $180.15 \%$ and LAI in $146.68 \%$. The herbicides did not cause any injury to the cupuassu tree or to the leguminous plants and provided over $60 \%$ of weed control.

Key words: weeds, native fruit tree, Theobroma grandiflorum, Amazonian region.

Recebido para publicação em 17.10.2002 e na forma revisada em 2.4.2003.

2 Eng.-Agr., Dr., Universidade Federal do Amazonas, Av. Gen. Octávio R.J. Ramos, 3000, 69077-000 Manaus-AM, <jfsilva@ufam.edu.br>. ${ }^{3}$ Eng.-Agr., Dr., Instituto Nacional de Pesquisa da Amazônia, Caixa Postal 478, 69011-970 ManausAM, <bueno@inpa.gov.br>. ${ }^{4}$ Eng.-Agr., Dra., Embrapa Amazônia Ocidental, Caixa Postal 319, 69011-970 Manaus-AM, $<$ claret@cpaa.embrapa.br>.

Planta Daninha, Viçosa-MG, v.21, n.1, p.137-143, 2003 


\section{INTRODUÇÃO}

O cupuaçu é uma das frutas mais populares da Amazônia. A sua polpa é usada para produzir sorvetes, sucos, compotas e doces diversos. Todavia, há problemas que dificultam a expansão do cultivo do cupuaçuzeiro, entre os quais o controle de plantas daninhas.

No Estado do Amazonas, o manejo das espécies de plantas daninhas ainda é feito com facão, raramente com enxada, e de forma mecânica, levando à compactação do solo nas entrelinhas. Na região há escassez de mão-de-obra no meio rural e o manejo manual é uma prática desconfortável, devido às condições climáticas: alta temperatura e umidade relativa do ar e densa radiação solar (Silva, 1999). O controle de plantas daninhas com herbicidas e/ou leguminosas ajudaria a reduzir a interferência dessas plantas no cultivo e na produção do cupuaçuzeiro, aumentando assim a produtividade das plantas e proporcionando melhores condições de trabalho para o agricultor.

O uso de leguminosas em cultivos perenes assume aspectos ecológicos, como recomposição da vegetação e melhorias das propriedades físicas, químicas e biológicas do solo (Canto, 1989), além de elas causarem supressão do crescimento das plantas daninhas (Almeida \& Rodrigues, 1985). A redução no crescimento destas plantas depende da quantidade de fitomassa seca produzida pelas leguminosas (Severino \& Christoffoleti, 2001). Portanto, o conteúdo de matéria seca nos órgãos das plantas e a área foliar são características importantes em estudos de biomassa e na seletividade de herbicidas (Schmidt, 1993), porque as plantas sob o efeito de herbicidas podem modificar o padrão de distribuição de fotoassimilados entre os seus órgãos (Griffins et al., 1984), modificando a relação entre a fonte e o dreno na partição da biomassa (Arruda et al., 1999), afetando assim a produção de matéria seca e a área foliar e, conseqüentemente, o índice de área foliar. A matéria seca da parte aérea e o índice de área foliar (IAF) das plantas de soja não foram alterados pelo uso de alachlor ou de haloxyfop e estão associados diretamente à interferência das plantas daninhas na produção das lavouras (Contreras et al., 1989; Durigan \& Victoria Filho, 1994; Fleck et al., 1995; Marenco \& Lopes, 1996).
Na avaliação da tolerância de soja, de Colopogonium mucunoides, Centrosema pubescens e Pueraria phaseoloides a herbicidas, tanto a matéria seca como a área foliar têm sido apontadas como boas indicadoras para estudo de seletividade de herbicidas a estas plantas (Cayon et al., 1990; Tan et al., 1977).

O objetivo deste trabalho foi avaliar a eficácia dos herbicidas alachlor e haloxyfop no controle das plantas daninhas e a seletividade em leguminosas de cobertura Mucuna cochinchinensis e Pueraria phaseoloides e em plantas jovens de cupuaçu.

\section{MATERIAL E MÉTODOS}

O experimento foi instalado na área experimental da Embrapa Amazônia Ocidental, em Manaus-AM. O solo, depois de arado e gradeado, foi amostrado e analisado, tendo sido obtidos os seguintes resultados quanto às características granulométricas: 429,6 g kgl de areia grossa, $119,1 \mathrm{~g} \mathrm{~kg}^{1}$ de areia fina, $68,3 \mathrm{~g} \mathrm{~kg}$ de silte e $383,0 \mathrm{~g} \mathrm{~kg}^{1}$ de argila, sendo classificado como areno-argiloso. A composição química das amostras revelou: $\mathrm{pH}(\mathrm{em}$ água 1:2,5) $=4,2 ; \mathrm{Al}=1,3 ; \mathrm{Ca}=0,33 ; \mathrm{Mg}=$ $0,12 \mathrm{cmol}_{\mathrm{c}} / \mathrm{kg} ; \mathrm{P}=4 ; \mathrm{K}=44 ; \mathrm{Zn}=0,51 ; \mathrm{Mn}=$ 1,3; $\mathrm{Cu}=0,24 ;$ e $\mathrm{Fe}=55 \mathrm{mg} \mathrm{kg}^{-1}$. O teor de matéria orgânica foi de $25,8 \mathrm{~g} \mathrm{k}^{1}$.

Adotou-se o delineamento experimental de blocos ao acaso, em faixas, com três blocos, (Pimentel Gomes, 1982), sendo as faixas constituídas de $M$. cochinchinensis e $P$. phaseoloides, semeadas em covas contendo $50 \mathrm{~kg} \mathrm{ha}^{1}$ de superfosfato triplo, distantes $1,20 \mathrm{~m}$ entre si e das plantas de cupuaçu. Antes da semeadura, as sementes de puerária foram colocadas em água a $85^{\circ} \mathrm{C}$ durante 15 minutos, para a quebra da dormência.

As covas para o plantio do cupuaçuzeiro mediram 0,40 × 0,40 ×0,40 m, espaçadas por $6 \mathrm{~m}$ entre si, contendo cada uma 10 litros de esterco de galinha, 1,0 kg de calcário dolomítico, $0,40 \mathrm{~kg}$ de Atifós e $0,20 \mathrm{~kg}$ de $\mathrm{P}_{2} \mathrm{O}_{5}$ na forma de superfosfato triplo.

Os herbicidas usados foram o alachlor (2-cloro-N-(2,6-dietilfenil)-N-(methoximetil) acetamida) (Laço), em pré-emergência, e 
haloxyfop-metil (metil 2-[4-[[3-cloro-5(trifluorometil)-2-oxi piridinil)] fenoxi] propanoato) Verdict, em pós-emergência (Ahrens, 1994). A não-aplicação do haloxyfop em pós-emergência precoce foi devido às leguminosas já estarem estabelecidas e ao nãoaparecimento de plantas daninhas antes da cobertura do solo pelas leguminosas. Quando as plantas daninhas emergiram no dossel das leguminosas, fez-se então a aplicação do haloxyfop.

Os tratamentos consistiram de quatro testemunhas e da aplicação de três doses dos herbicidas alachlor e haloxyfop, sendo: 1 Testemunha sem capina e sem leguminosas; 2 - Testemunha sem capina e com leguminosas; 3 - Testemunha com capina e sem leguminosas; 4 - Testemunha com capina e com leguminosas; 5 - Haloxyfop 0,06 $\mathrm{kg}$ ha' ${ }^{1}$ i.a.; 6 - Haloxyfop 0,12 kg hal i.a.; 7 - Haloxyfop $0,24 \mathrm{~kg}$ hà i.a.; 8 - Alachlor $1,0 \mathrm{~kg} \mathrm{ha}^{1}$ i.a.; 9 - Alachlor 2,0 kg ha i.a.; 10 - Alachlor $4,0 \mathrm{~kg}$ hà i.a.

Usou-se um pulverizador de aço inox, costal, com pressão constante de $40 \mathrm{lb} \mathrm{pol}^{-2}$, mantida com injeção de $\mathrm{CO}_{2}$ e barra de aplicação com quatro bicos XR80.02, espaçados $0,50 \mathrm{~m}$ entre si. A quantidade de calda herbicídica usada na aplicação de alachlor, logo após a semeadura das leguminosas, foi de 252 L had. Adicionou-se o adjuvante Assist na calda de haloxyfop na proporção de $0,5 \% \mathrm{v} / \mathrm{v}$, com volume de calda de $260 \mathrm{~L}$ ha' .

Para a amostragem das plantas daninhas foi utilizado um retângulo de $0,012 \mathrm{~m}^{2}$ de área, sendo atirado, aleatoriamente, na área útil de cada parcela, na faixa de cada leguminosa. As plantas dentro do retângulo foram cortadas rente à superfície do solo e levadas para laboratório, onde foram classificadas por família, gênero e espécie e separadas folhas, pecíolos e caules, os quais foram secos em estufa de ventilação forçada a $75{ }^{\circ} \mathrm{C}$, até peso constante.

$\mathrm{O}$ índice de área foliar (IAF) foi calculado segundo Fisher (1984). Os dados da dose zero considerados nas Figuras 1 a 4 são da testemunha sem capina e sem leguminosa.

Os dados foram submetidos à análise de variância pelo teste $\mathrm{F}(\mathrm{p}<0,05)$, que mostrou não haver diferença entre as leguminosas e interação destas com os herbicidas para as características do cupuaçuzeiro. A seleção das equações de regressão para leguminosas e plantas daninhas foi para as características que apresentaram significância (ANOVA), maior coeficiente de determinação e tendência com os dados originais.

As análises foram realizadas com o auxílio do programa SANEST, cujos dados de peso da matéria seca das plantas daninhas, das leguminosas e do cupuaçuzeiro foram transformados para $\sqrt{x+0,5}$, para efeito de análise de variância.

\section{RESULTADOS E DISCUSSÃO}

As plantas daninhas que ocorreram na área do experimento foram: Bisonia crispa, Brachiaria cf. Brizantha, Cecropia spp., Croton lobatus, Croton miquelensis, Cyperus esculentus, Homolepis anturiensis, Jacaranda copaia, Lantana camara, Mimosa spruceana, Panicum laxum, Passiflora nitida, Paspalum urvillei, Peninsetum purpureum, Phylanthus niruri, Scleria pterota, Spermacoce latifolia, Sida rhombifolia, Solanum grandiflorum e Stachytarpheta cayennensis.

As espécies pertencentes à família Poaceae representam $23,80 \%$ das encontradas na área, enquanto Euphorbiaceae e Malpighiaceae representam $14,28 \%$ cada, seguidas de Cyperaceae e Verbenaceae, com 9,25\% cada, e das demais, com 4,76\%. As Poaceae apresentaram mais de $70 \%$ da matéria seca da parte aérea das plantas daninhas. Resultados semelhantes foram encontrados por Valenzuela (1990) em cacauais.

A aplicação de haloxyfop reduziu o peso da matéria seca das plantas daninhas totais de $375 \mathrm{~g} \mathrm{~m}^{2}$ (dose zero) para $175 \mathrm{~g} \mathrm{~m}^{2}$ (dose de $0,24 \mathrm{~kg} \mathrm{ha}^{1}$ i.a.) e também o valor do IAF, de 1,8 para 0,75 , nas doses de 0 e $0,24 \mathrm{~kg} \mathrm{ha}^{1}$ i.a., respectivamente. Em relação às leguminosas, houve produção máxima estimada de matéria seca $\left(323,99 \mathrm{~g} \mathrm{~m} \mathrm{~m}^{2}\right)$ e $\operatorname{IAF}(1,59)$, na dose de $0,12 \mathrm{~kg}$ hal i.a., e no valor do IAF das plantas daninhas totais (Figuras 1 e 2). O efeito estimulador deste produto sobre as características das leguminosas atingiu a produção máxima estimada de matéria seca $(323,99 \mathrm{~g}$ mî) e IAF $(1,59)$ na dose de $0,12 \mathrm{~kg} \mathrm{ha}^{1}$ i.a. de haloxyfop. A partir desta dose houve decréscimo, alcançando a menor produção de matéria seca 
$\left(179,84 \mathrm{~g} \mathrm{~m}^{2}\right)$ na dose de $0,24 \mathrm{~kg} \mathrm{ha}^{1}$ i.a. e do valor de IAF $(1,08)$ na dose zero (Figuras 1 e 2 ). Os valores dessas características das leguminosas, na maior dose e na dose zero, são muito próximos, indicando que este herbicida apenas estimulou o crescimento das leguminosas nesse intervalo de doses.

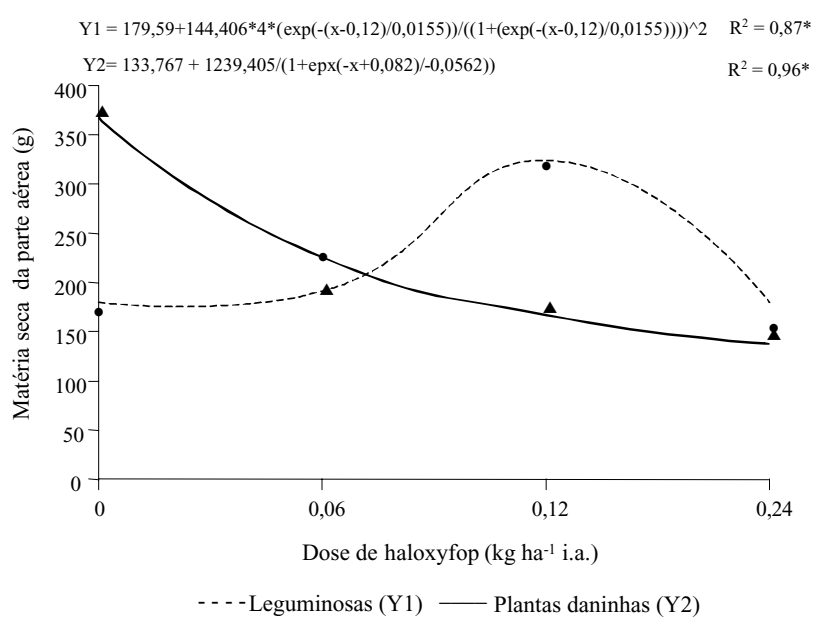

Figura 1 - Efeitos de doses de haloxyfop sobre o peso da matéria seca das leguminosas, em campo. Manaus-AM.

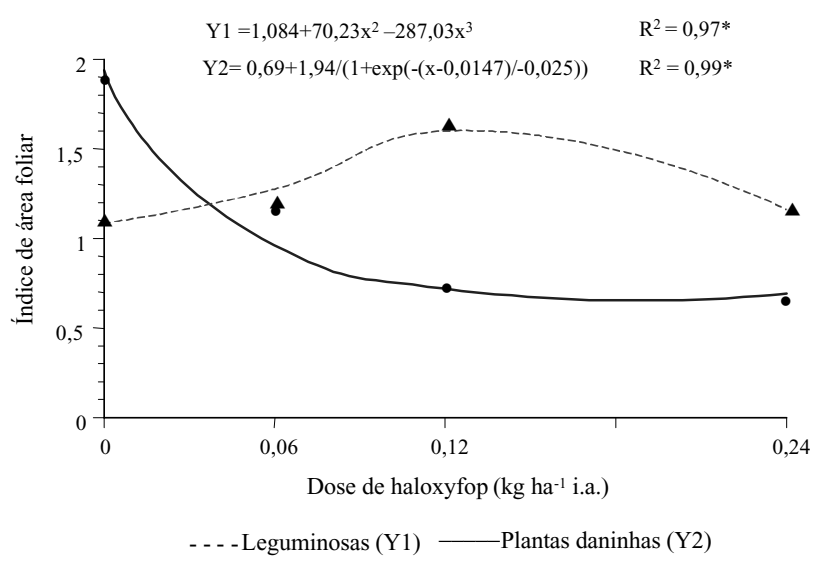

Figura 2 - Efeitos de doses de haloxyfop sobre o índice de área foliar das leguminosas e das plantas daninhas. Manaus-AM.

O comportamento da produção de matéria seca e o valor do IAF em função das doses do haloxyfop seguem a mesma tendência de resposta. Como o herbicida reduziu a área foliar das plantas daninhas, o IAF foi também afetado. Esta característica tem grande influência na interceptação da luz, refletindo, portanto, diretamente na produção de matéria seca das plantas daninhas (Figuras 1 e 2).

O efeito do haloxyfop na dose de $0,099 \mathrm{~kg}$ hà i.a. (derivada primeira) induziu nas leguminosas maior taxa de crescimento de matéria seca (Figura 1) e, na dose de $0,16 \mathrm{~kg}$ hà i.a., maior valor de IAF (Figura 2). O estímulo do crescimento de plantas por herbicidas é relatado por vários autores (Streibig, 1988; Brain \& Cousens, 1989; Devine et al., 1993; Silva, 1999). Em cultura de células de milho e de soja adicionada de 0,01 $\mu \mathrm{g}$ de haloxyfop foi constatado que o herbicida aumentou, em 600 e $400 \%$, respectivamente, o peso da matéria fresca das células (Cho et al., 1986).

O estímulo ao crescimento das leguminosas pode ter sido causado por efeito secundário do herbicida nas rotas do metabolismo secundário (Devine et al., 1993).

A resposta do tipo sigmoidal do peso de matéria seca das plantas daninhas ao haloxyfop teve a produção máxima na testemunha $\left(367,53 \mathrm{~g} \mathrm{~m} \mathrm{~m}^{2}\right)$ e a menor produção $\left(137,78 \mathrm{~g} \mathrm{~m}^{2}\right)$ na maior dose do herbicida $\left(0,24 \mathrm{~kg} \mathrm{ha}^{1}\right.$ i.a. $)$ (Figura 1). O aumento do controle com o aumento da dose do herbicida deve ter ocorrido em razão de a população dominante de plantas daninhas ser da família Poaceae.

O controle mediano (62\%) das plantas daninhas na maior dose de haloxyfop em relação à testemunha, avaliado por meio do peso da matéria seca, pode ser atribuído, em parte, ao estádio de crescimento avançado das plantas daninhas. Entretanto, quando aplicado em pós-emergência precoce em Cynodon dactylon, na dose de $0,25 \mathrm{~kg} \mathrm{ha}^{1}$ i.a., o herbicida apresentou controle acima de 89\% (Abdullahi et al., 2001).

A produção de matéria seca das leguminosas alcançou o valor máximo estimado na dose zero $\left(170,20 \mathrm{~g} \mathrm{~m}^{2}\right)$ e o mínimo na dose de $4,0 \mathrm{~kg} \mathrm{ha}{ }^{1}$ i.a. $\left(123,75 \mathrm{~g} \mathrm{~m}^{2}\right)$ (Figura 3) de alachlor. Comportamento semelhante teve o IAF, cujo valor na dose zero foi de 1,81 , e na dose de 4,0 kg ha1 i.a. foi de 1,15 (Figura 4). A redução de $29,28 \%$ no acúmulo da matéria seca da parte aérea das leguminosas, causada pelo 
efeito da dose de $4,0 \mathrm{~kg} \mathrm{ha}{ }^{1}$ i.a. de alachlor, evidencia que, apesar da tolerância das leguminosas ao produto, é pequeno o intervalo entre a dose tolerada e a dose de forte injúria ou de controle. Por essa razão, a dose de alachlor mostrou ser fator relevante na seletividade do produto às leguminosas.

Maior acúmulo de matéria seca da parte aérea das plantas daninhas ocorreu na testemunha sem herbicida $\left(383,59 \mathrm{~g} \mathrm{~m}^{2}\right)$. A maior dose de alachlor $\left(4,0 \mathrm{~kg}^{\mathrm{h}} \mathrm{a}^{1}\right.$ i.a.) reduziu a matéria seca da parte aérea dessas plantas a 93,58 g m² (Figura 3). De maneira análoga, o IAF estimado das plantas daninhas, na dose zero de alachlor, foi de 1,86 , enquanto na maior dose do produto ele reduziu para 0,67 (Figura 4). O comportamento da produção de matéria seca e os valores de IAF das plantas daninhas e das leguminosas foram idênticos (Figuras 3 e 4). Também deve ter contribuído para a redução da matéria seca acumulada da parte aérea das plantas daninhas o fato de que no ano de condução do experimento ocorreu o "El Niño", que reduziu drasticamente a precipitação e, conseqüentemente, o teor de água no solo. Essas condições, segundo Putnam \& Rice (1979), podem aumentar o nível de injúria do alachlor às plantas.

Em relação ao cupuaçuzeiro, o número de folhas na testemunha livre de interferência das plantas daninhas e leguminosas, com capina e sem leguminosas (Tabela 1), foi maior do que

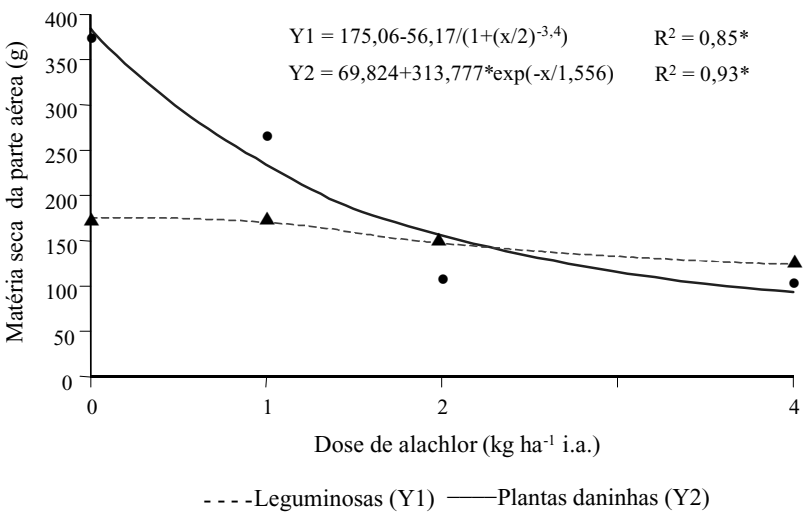

Figura 3 - Efeitos de doses de alachlor sobre o peso da matéria seca da parte aérea das leguminosas e das plantas daninhas. Manaus-AM.

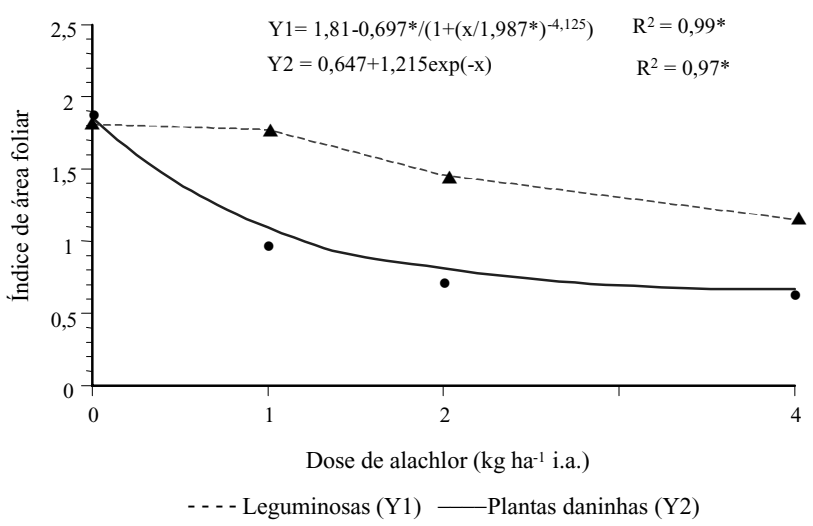

Figura 4 - Efeitos de doses de alachlor sobre o índice de área foliar das leguminosas e plantas daninhas. Manaus-AM.

Tabela 1 - Número de folhas, altura e diâmetro das plantas de cupuaçuzeiro em consórcio com leguminosas, sob influência de doses de herbicidas e níveis de plantas daninhas, em campo. Manaus-AM. 1996*

\begin{tabular}{|l|c|c|c|}
\hline \multicolumn{1}{|c|}{ Herbicida } & \multicolumn{3}{|c|}{ Característica } \\
\cline { 2 - 4 } & Número de folhas & $\begin{array}{c}\text { Altura } \\
\text { (cm) }\end{array}$ & $\begin{array}{c}\text { Diâmetro } \\
(\mathrm{mm})\end{array}$ \\
\hline Testemunha sem capina e sem leguminosas & $53 \mathrm{bc}$ & $92 \mathrm{c}$ & $16,7 \mathrm{ab}$ \\
Testemunha sem capina e com leguminosas & $38 \mathrm{bc}$ & $92 \mathrm{c}$ & $17,0 \mathrm{ab}$ \\
Testemunha com capina e sem leguminosas & $84 \mathrm{a}$ & $112 \mathrm{a}$ & $19,0 \mathrm{a}$ \\
Testemunha com capina e com leguminosas & $59 \mathrm{ab}$ & $109 \mathrm{ab}$ & $19,0 \mathrm{a}$ \\
Haloxyfop 0,06 kg ha ${ }^{-1}$ i.a. & $34 \mathrm{c}$ & $99 \mathrm{ab}$ & $16,8 \mathrm{ab}$ \\
Haloxyfop 0,12 kg ha ${ }^{-1}$ i.a. & $37 \mathrm{bc}$ & $95 \mathrm{bc}$ & $16,1 \mathrm{~b}$ \\
Haloxyfop 0,24 kg ha ${ }^{-1}$ i.a. & $46 \mathrm{bc}$ & $99 \mathrm{ab}$ & $17,4 \mathrm{ab}$ \\
Alachlor 1 kg ha-1 i.a. & $48 \mathrm{bc}$ & $97 \mathrm{bc}$ & $17,3 \mathrm{ab}$ \\
Alachlor 2 kg ha & $46 \mathrm{bc}$ & $96 \mathrm{bc}$ & $17,11 \mathrm{ab}$ \\
Alachlor 4 kg ha & $60 \mathrm{ab}$ & $96 \mathrm{bc}$ & $18,10 \mathrm{ab}$ \\
CV (\%) & 20,79 & 6,06 & 6,78 \\
\hline
\end{tabular}

* Médias seguidas pela mesma letra, na coluna, não diferem entre si a 5\% de probabilidade pelo teste de Tukey. 
nos demais tratamentos, muito embora não tenha diferido da testemunha capinada com leguminosa e do alachlor ( $4 \mathrm{~kg} \mathrm{ha}^{1}$ i.a.) nos níveis de significância testados.

Quanto à altura do cupuaçuzeiro (Tabela 1), os efeitos das testemunhas com capina e haloxyfop $(0,06$ e $0,12 \mathrm{~kg}$ hal i.a.) não diferiram entre si.

Para o diâmetro (Tabela 1) do caule, as testemunhas com capina não foram diferentes entre si, mas foram superiores apenas ao diâmetro sob o efeito da dose de $0,12 \mathrm{~kg}$ hà i.a. de haloxyfop. Nesta dose houve a maior produção de matéria seca das leguminosas, o que pode ter causado interferência nessa característica do cupuaçuzeiro.

Souza et al. (1992) avaliaram 20 clones de cupuaçuzeiro com 12 meses de idade e obtiveram valores médios de altura da planta e diâmetro do caule relativamente superiores ( $1,54 \mathrm{~m} \mathrm{e} \mathrm{2,6} \mathrm{cm,} \mathrm{respectivamente)} \mathrm{aos} \mathrm{obtidos}$ neste experimento. Essas diferenças podem ser explicadas, em parte, pelo efeito do "El Niño", que diminuiu o teor de água no solo no ambiente estudado (dados não apresentados). As plantas de cupuaçu, livres da interferência das plantas daninhas e das leguminosas, obtiveram valores mais próximos aos encontrados por aqueles autores.

A interferência de plantas daninhas nas plantas de cacau até os três anos de idade, de acordo com estudo de Reyes (1970) e Akobundu (1987), pode retardar o crescimento e o desenvolvimento do cacaueiro, pois nesta idade a maior parte do sistema radicular está em estreita proximidade com as plantas daninhas que crescem ao seu redor e sobre a superfície. Resultados semelhantes foram obtidos por Cruz et al. (1984), que eliminaram a interferência da população de plantas daninhas, após 60 dias, com paraquat $0,20 \mathrm{~kg} \mathrm{ha}^{1}$ mais diuron $2,40 \mathrm{~kg} \mathrm{ha}^{1}$ e sulfosate $2,40 \mathrm{~kg} \mathrm{ha}{ }^{1}$, em cacauais com quatro anos de idade, proporcionando o aumento do diâmetro do tronco da planta de cacau em relação à testemunha não capinada.

Os herbicidas usados não apresentaram efeitos tóxicos visuais às plantas de cupuaçuzeiro e às leguminosas, exceto o alachlor, que na maior dose retardou o crescimento da puerária nas duas primeiras semanas após sua emergência.

\section{AGRADECIMENTOS}

Ao Renato Argolo de Souza, pela revisão do texto, à Maria Regina Marinho, pela correção do Abstract, e ao técnico de laboratório Gilsimar Brito de Melo, pelo auxílio na condução do experimento.

\section{LITERATURA CITADA}

ABDULlAHI, A. E. et al. Cynodon dactylon control in sunflower (Helianthus annuus) with postemergence graminicides in a semi-arid environment. Crop Protec., v. 20, n. 5, p. 411-414, 2001.

AHRENS, W. H. Herbicide handbook. 7.ed. Champaign: 1994. $352 \mathrm{p}$.

AKOBUNDU, I. O. Weed science in integrated pest management. In: KLIGMAN, G. C.; ASHTON, F. M.; NOORDHOFF, L. J. Weed science in the tropics: Principles and practices. New York: John Wiley, 1987. p. 1-22.

ALMEIDA, F. S.; RODRIGUES, B. N. Guia de herbicidas; recomendações para uso em plantio direto e convencional. Londrina: IAPAR, 1985. 468 p.

ARRUDA, J. S.; LOPES, N. F.; BACARIN, M. A. Crescimento de plantas de soja em função de doses de sulfentrazone. Planta Daninha, v. 7, n. 3, p. 375-386, 1999.

BRAIN, P.; COUSENS, R. To describe dose responses where there is stimulation of growth at low doses. Weed Res., v. 29, p. 93-96, 1989.

CANTO, A. C. Importância ecológica do uso de leguminosas como plantas de cobertura em guaranazais no Estado do Amazonas. 1989. 121 f. Tese (Doutorado em Ecologia) - Instituto Nacional de Pesquisa da Amazônia, Manaus, 1989.

CAYON, D. G. et al. Tolerância e crescimento da soja (Glycine max (L.) Merril) tratada com imazaquin. R. Bras. Fisiol. Veg., v. 2, p. 25-32, 1990.

CHO, H. Y.; WIDHOLM, J. M.; SLIFE, F. W. Effect of haloxyfop on corn (Zea mays) and soybean (Glycine max) cell suspension cultures. Weed Sci., v. 43, p. 496-501, 1986.

CONTRERAS, E.; CHI. D. M.; VIEIRA, J. Evaluación ecofisiologica de cultivos associados. II. Canavalia-Maiz. Agron. Trop., v. 39, n. 1-3, p. 45-61, 1989. 
CRUZ, L. S. P. et al. Influência do herbicida sistêmico sulphosate, aplicado isolado e em misturas com herbicidas residuais, sobre algumas características fisiológicas do cacau (Theobroma cacau L.) e sobre as plantas daninhas. Resultados preliminares. In: CONGRESSO BRASILEIRO DE HERBICIDAS E PLANTAS DANINHAS, 1984, Belo Horizonte. Resumos... Belo Horizonte: 1984. p. 136.

DEVINE, M. D.; DUKE, S. O.; FEDTKE, C. Physiology of herbicide action. New Jersey: PTR Prentice Hall, 1993. $441 \mathrm{p}$.

DURIGAN, J. C.; VICTORIA FILHO, R. Comportamento de baixas doses de herbicidas na cultura da soja (Glycine $\max ($ L.) Merrill. II. Efeitos sobre o controle das plantas daninhas, desenvolvimento e absorção de nutrientes pela cultura. Planta Daninha, v. 7, n. 1, p. 22-40, 1994.

FISHER, N. M. Crop growth and development: the vegetative phase. In: GOLDSWORTHY, P. R.; FISHER, N. M. (Eds.) The physiology of tropical field crops. New York: John Wiley, 1984. p. 119-161, 1984.

FLECK, N. G.; VARGAS, L. I; DA CUNHA, M. M. Controle de plantas daninhas em soja com doses reduzidas de herbicidas. Planta Daninha, v. 13, n. 2, p. 117-123, 1995.

GRIFFINS, J. L. et al. Forage legumes response to dicamba e 2,4-D applications. Agron. J., v. 76, p. 487-490, 1984.

MARENCO, R. A.; LOPES, N. F. Assimilate partitioning and phytotoxicity in soybean plants treated with herbicides. Planta Daninha, v. 14, n. 1, p. 48-54, 1996.

PIMENTEL GOMES, F. Curso de estatística experimental. 10.ed. Piracicaba: ESALQ, 1982. 430 p.

PUTNAM, A. R.; RICE, R. P. Environmental and edaphic influences on the selectivity of alachlor on snap bean (Phaseolus vulgaris). Weed Sci., v. 27, p. 570-574, 1979.
REYES, E. H. Las malezas en el cacaotero y su control. Cacao, v. 15, p. 10-15, 1970.

SCHMIDT, R. R. Development of herbicides-role of bioassays. In: STREIBIG, J. C.; KUDSK, P. (Eds.). Herbicides bioassays. Boca Raton: CRC Press, 1993. p. 8-24.

SEVERINO, F. J.; CHRISTOFFOLETI, P. J. Efeitos de quantidades de fitomassa de adubos verdes na supressão de plantas daninhas. Planta Daninha, v. 19, n. 2, p. 223-228, 2001.

SILVA, J. F. Influência de herbicidas no crescimento e anatomia da epiderme foliar de plantas de cupuaçu (Theobroma grandiflorum (Willdenow ex Spreng) Schumann) e leguminosas em consorciação. 1999. $171 \mathrm{f}$. Tese (Doutorado em Botânica) - Instituto Nacional de Pesquisa da Amazônia, Manaus, 1999.

SOUZA, A. G. C.; GUIMARÃES, R. R.; NUNES, C. D. M. Avaliação preliminar de clones de cupuaçuzeiro (Theobroma grandiflorum (Willd ex Spreng ) Schum), nas condições de Manaus-AM. I Vigor da planta. Manaus: EMBRAPACPAA, 1992. p. 1-5 (Pesquisa em Andamento, 13, EMBRAPA-CPAA).

STREIBIG, J. C. Herbicide bioassay. Weed Res., v. 28, p. 497-484, 1988.

TAN, H. T.; PILLAI, K. R.; FUA, J. M. Establishment of legume covers using pre-and post-emergence herbicides. In: EARD, D. A.; NEWALL, W. (Eds.) International developments in oil palm. Kuala Lumpur, 1977. p. 471484 .

VALENZUELA, J. A. D. Leguminosas de cobertura em cacau (Theobroma cacao L.) y pejibaye (Bactris gasipaes H. B. K.). 1990. 85 f. Tese (Mestrado em Fitoprotection) - Centro Agronomico Tropical de Investigación y Enseñanza, Turialba, 1990. 